
\title{
25 Research Sourere \\ Multifocal IOL Explantation in Patients with Opaque Lentis after Refractive Lens Exchange
}

\author{
Maria Phylactou ( $\nabla$ phylactou.maria@gmail.com ) \\ Moorfields Eye Hospital https://orcid.org/0000-0002-3471-8913 \\ Nizar Din \\ Moorfields Eye Hospital \\ Francesco Matarazzo \\ Moorfields Eye Hospital \\ Vincenzo Maurino \\ Moorfields Eye Hospital
}

\section{Research Article}

Keywords: IOL exchange, IOL opacification, IOL explantation, Lentis, Oculentis, Refractive lens exchange

Posted Date: May 26th, 2021

DOI: https://doi.org/10.21203/rs.3.rs-186410/v1

License: (9) This work is licensed under a Creative Commons Attribution 4.0 International License.

Read Full License

Version of Record: A version of this preprint was published at International Ophthalmology on October 8th, 2021. See the published version at https://doi.org/10.1007/s10792-021-02072-w. 


\section{Abstract \\ Purpose}

We describe the outcomes of intraocular lens (IOL) explantation in a cluster of opaque multifocal Lentis LS-313 following refractive lens exchange (RLE).

\section{Methods}

Single-centre, single-surgeon, retrospective case series.

\section{Results}

The study enrolled 10 eyes of 10 patients, 6 male and 4 female. All patients had uneventful RLE with multifocal IOL implantation. The mean patient age at the time of RLE was 53 years \pm 2.52 (SD). Two eyes had YAG laser capsulotomy prior explantation. The mean interval between the initial RLE and IOL explantation was 5.4 years \pm 1.4 (SD). IOL exchange was performed in all eyes in one procedure. Five eyes had in the bag hydrophobic acrylic IOL (3 multifocal and 2 monofocal) three eyes had 3-piece hydrophobic acrylic IOL in the ciliary sulcus and two had an anterior chamber IOL. Intraoperatively one patient had weak zonules and two patients had zonular dehiscence and required anterior vitrectomy. The mean preoperative CDVA was $0.25 \pm 0.15$ (SD) logMAR and at the final follow-up, improved to $0.00 \pm 0.07$ $(S D) \log M A R(p<0.01)$. Light microscopy with von Kossa stain confirmed IOL calcification. No postoperative complications were recorded.

\section{Conclusions}

IOL exchange appears to be a feasible and safe surgical option for multifocal IOL opacification. However, patients must be warned of additional intraoperative risks including zonular dialysis, vitreous loss, retinal detachment and need for potential ACIOL with its associated sequel of complications. Moreover, YAG laser capsulotomy should be considered carefully as increases the chances of intraoperative complications and restricts the surgical options of secondary IOL insertion, including in-the-bag IOL exchange with MFIOL.

\section{Introduction}

Refractive lens exchange (RLE) is a variation of standard cataract surgery. It is a refractive procedure aiming for spectacle independence by removing the crystalline lens in the absence of clinically significant lens opacity. Suitable candidates are usually presbyopic patients over the 5th decade of life with high refractive errors, unsuitable for laser vision correction or phakic intraocular lens. RLE with multifocal IOL 
(MFIOL) implantation has become widely accepted as an effective method for gaining spectacle independence in this patient group, as it increases depth of field and enhances near vision. ${ }^{1-4}$

Intraocular Lens (IOL) opacification is a relatively rare but reported complication of intraocular surgery impeding vision and often necessitates the need for an IOL explantation. In 2014, Oculentis GmbH (Germany) issued a Field Safety Notice ${ }^{A}$ requesting a mass recall of all LENTIS HydroSmart foldable intraocular lenses, following reports of postoperative IOL opacification. A sequel Field Safety Notice ${ }^{B}$ followed in September 2017, and included all LENTIS foldable Intraocular lenses with model numbers starting with L-, LU- and LS- and having an expiry date between January 2017 and May 2020.

Oculentis reported that 1,386 IOL cases have been registered as opacified in the United Kingdom. Studies $^{C}$ by the manufacturer have indicated that surface calcification could possibly be the result of phosphate remnants originating from a detergent previously used in the cleaning process of the IOL. Although the cause of IOL opacification is multifactorial, residues could make the IOL under certain conditions more prone to opacification. The company advised IOL exchange as the only recommended treatment for post-operative opacification if the visual acuity is compromised in the face of the patient's individual conditions and needs.

In this case series, we report the outcomes of IOL explantation in a cluster of opaque multifocal IOL (Lentis LS-313, Oculentis GmbH, Germany), after refractive lens exchange.

\section{Material And Methods}

This study was a retrospective case series, of 10 eyes of 10 patients that underwent IOL exchange due to IOL opacification. Consecutive patients that underwent uneventful RLE with a multifocal IOL (Lentis LS313), between 2011-2015, by different surgeons in different hospitals, were referred to our department with significant reduction in visual acuity due to postoperative IOL opacification. IOL exchange performed by a single surgeon, at a single centre, from 2017 to 2019 . The indication for IOL explanation was a clinically significant reduction in visual acuity. The study was approved by the Clinical Audit and Effectiveness Committee of Moorfields Eye Hospital and was adhered to the tenets of the Declaration of Helsinki.

Patients' demographics including age, gender, laterality, ophthalmic and general medical history were included. Cataract surgery data collected, including date of IOL implantation, IOL serial number, intraoperative and postoperative complications, and postoperative visual acuity and refraction. Furthermore, additional postoperative interventions including secondary surgical procedures or laser treatment were recorded. The diagnosis of IOL opacification was established on slit-lamp and IOL explantation offered to the patients with symptomatic visual impairment.

Routine postoperative medication included Choramphenicol 0.5\% (Bausch \& Lomb, Aubenas - France) eye drops 4 times daily for 2 week, and a tapering dose of topical Dexemethasone $0.1 \%$ (Maxidex - SA Alcon-Couvreur NV, Belgium) 2 hourly for 2 weeks and then reducing 1 drop weekly. All patients 
underwent routine examination preoperatively and 4 weeks and 12 weeks postoperatively, including corrected distance visual acuity (CDVA), refraction, slit-lamp biomicroscopy, applanation tonometry and fundoscopy.

Statistical analysis was performed using Stata â (StataCorp. 2015. Stata Statistical Software: Release 14. College Station, TX: StataCorp LP). An independent t-test was used to compare the averages. A value of $p<0.05$ was defined as statistically significant.

\section{Surgical Technique}

The Lentis LS-313 is a foldable, one-piece, rectangular shape lens and it consists of a co-polymer hydrophilic acrylic core with a hydrophobic surface coating.

The main surgical challenge in these cases is the chronically fibrosed capsule leading to strong adhesions between the capsular bag and the orthogonal-shaped IOL. The aim is to gently break these adhesions by applying opposite direction tangential forces between the IOL and the capsular bag to minimise zonular pressure. Additional enlargement of previous capsulorhexis may be required, particularly in small capsulorhexis opening or if anterior capsular phimosis is present. Dispersive ophthalmic viscosurgical devices (OVD) is used to protect the endothelium and with the aid of a fine iris repositor or IOL manipulator, the adhesions are broken and the opacified IOL is delivered into the anterior chamber (AC). Visco- and BSS- dissection is also used to hydrate and weaken the cicatricial adhesions as required. Once in the $A C$, the $\mathrm{IOL}$ is cut in half using micro-surgical intraocular scissors (MST) before being explanted through a $3.0 \mathrm{~mm}$ temporal corneal tunnel incision, leaving the capsular bag intact (Figure 1). Additional difficulties arise in cases where a posterior Nd:YAG laser capsulotomy is performed prior to explantation, making more difficult in-the-bag or ciliary sulcus secondary IOL fixation.

Explanted IOLs were sent to the laboratory for analysis, where gross and microscopic analysis were performed before and after histochemical staining for calcium (Figure 2).

\section{Results}

The study enrolled 10 eyes of 10 patients, 6 male and 4 female. The mean patient age at the time of refractive lens exchange was 53 years \pm 2.52 (SD) (range 51 to 63 years). All patients had uneventful phacoemulsification and implantation of multifocal IOL, Lentis LS-313 (M15 or M30). The mean axial length was $26.23 \pm 2.12 \mathrm{~mm}$ (range $21.28-27.61 \mathrm{~mm}$ ), the average IOL power was 13 dioptres (D) (range 9.5-26.5) and 7 patients had LS-313/MF15 and 3 patients LS-313/MF30. Two of these eyes had neodumium-doped yttrium aluminum garnet (Nd:YAG) laser capsulotomy after RLE. No other ocular or medical comorbidities were recorded. The mean interval between the initial RLE and IOL explantation was 5.4 years $\pm 1.4(\mathrm{SD})$, (range 4 to 8 years [ $64.5 \pm 16.7$ months]). IOL explantation and secondary IOL implantation was performed in all eyes in a single-step procedure. Five eyes had in the bag hydrophobic acrylic IOL, three had 3-piece hydrophobic acrylic IOL in the ciliary sulcus and two had an anterior chamber IOL. Three out of five eyes had in the bag secondary multifocal IOL implant (Table 1, Patients 
1,3 and 4). Intraoperative complications included one patient with weak zonules but enough capsular support for a sulcus IOL implant and two patients with intraoperative zonular dehiscence that required anterior vitrectomy and ACIOL (Table 1, Patient 6,8 ). All patients attended a postoperative review in 4and 12- weeks time. No postoperative complications were observed. There was statistical significant improvement in CDVA $(p<0.01)$. The mean preoperative CDVA was $0.25 \pm 0.15(S D) \log M A R$ and at the final follow-up, the mean CDVA improved to $0.00 \pm 0.07$ (SD) logMAR. All eyes had an improvement in CDVA after IOL exchange (Fig. 3).

\begin{tabular}{|c|c|c|c|c|c|c|c|c|}
\hline Patient & $\begin{array}{l}\text { Age/ } \\
\text { Gender/ } \\
\text { Eye } \\
\end{array}$ & $\begin{array}{l}\text { IOL } \\
\text { Model }\end{array}$ & $\begin{array}{l}\text { Phako } \\
\& \text { IOL } \\
\text { Year }\end{array}$ & $\begin{array}{l}\text { YAG } \\
\text { Laser }\end{array}$ & $\begin{array}{l}\text { Secondary } \\
\text { IOL implant } \\
\text { Position/Year }\end{array}$ & $\begin{array}{l}\text { Anterior } \\
\text { Vitrectomy }\end{array}$ & $\begin{array}{l}\text { Intraoperative } \\
\text { Complications }\end{array}$ & $\begin{array}{l}\text { Postoperative } \\
\text { Complications }\end{array}$ \\
\hline 1 & $58 / F / L$ & $\begin{array}{l}\text { LS-313 } \\
\text { MF15 }\end{array}$ & 2014 & No & $\begin{array}{l}\text { AT LISA tri83 } \\
\text { Bag/2019 }\end{array}$ & No & No & No \\
\hline 2 & $71 / F / R$ & $\begin{array}{l}\text { LS-313 } \\
\text { MF30 }\end{array}$ & 2011 & No & $\begin{array}{l}\text { MA60AC } \\
\text { Bag/2019 }\end{array}$ & No & No & No \\
\hline 3 & 78/M/R & $\begin{array}{l}\text { LS-313 } \\
\text { MF30 }\end{array}$ & 2012 & No & $\begin{array}{l}\text { AT LISA tri83 } \\
\mathrm{Bag} / 2018\end{array}$ & No & No & No \\
\hline 4 & 69/M/R & $\begin{array}{l}\text { LS-313 } \\
\text { MF15 }\end{array}$ & 2013 & No & $\begin{array}{l}\text { CT Lucia } 611 \\
\text { Bag/2017 }\end{array}$ & No & No & No \\
\hline 5 & $59 / \mathrm{F} / \mathrm{L}$ & $\begin{array}{l}\text { LS-313 } \\
\text { MF15 }\end{array}$ & 2014 & No & $\begin{array}{l}\text { MA60AC } \\
\text { Sulcus/2019 }\end{array}$ & No & No & No \\
\hline 6 & $66 / \mathrm{M} / \mathrm{R}$ & $\begin{array}{l}\text { LS-313 } \\
\text { MF15 }\end{array}$ & 2012 & No & $\begin{array}{l}\text { MTA4U0 } \\
\text { AC/2018 }\end{array}$ & Yes & $\begin{array}{l}\text { Zonular } \\
\text { dehiscence }\end{array}$ & No \\
\hline 7 & 72/M/L & $\begin{array}{l}\text { LS-313 } \\
\text { MF15 }\end{array}$ & 2015 & No & $\begin{array}{l}\text { MA60AC } \\
\text { Sulcus/2019 }\end{array}$ & No & No & No \\
\hline 8 & $72 / \mathrm{M} / \mathrm{L}$ & & 2012 & Yes & $\begin{array}{l}\text { MTA4U0 } \\
\text { AC/2019 }\end{array}$ & Yes & $\begin{array}{l}\text { Zonular } \\
\text { dehiscence }\end{array}$ & No \\
\hline 9 & $70 / \mathrm{M} / \mathrm{R}$ & $\begin{array}{l}\text { LS-313 } \\
\text { MF15 }\end{array}$ & 2012 & No & $\begin{array}{l}\text { SN60WF } \\
\text { Bag/2019 }\end{array}$ & No & No & No \\
\hline 10 & $68 / F / L$ & $\begin{array}{l}\text { LS-313 } \\
\text { MF15 }\end{array}$ & 2014 & Yes & $\begin{array}{l}\text { MA60AC } \\
\text { Sulcus/2019 }\end{array}$ & No & Weak zonules & No \\
\hline & & $\begin{array}{l}\text { LS-313 } \\
\text { MF30 }\end{array}$ & & & & & & \\
\hline
\end{tabular}

Gross examination of the explanted IOL showed a diffused whitish discoloration (Fig. 2a). Light microscopy examination with haematoxylin and eosin-stained sections as well as PAS-stained sections revealed a hint of a profile and a couple of chronic inflammatory cells. The von Kossa stain demonstrated the outline of the optic and haptics with stippled material, which is consistent with calcification (Fig. 2b). 
Intraocular lens explantation occurs in less than $1 \%$ of all cataract surgeries. The main reason for IOL removal is late dislocation of IOL due to zonular weakness. Other rare indications are IOL decentration, IOL opacification, incorrect IOL power, glare, and chafing syndrome ${ }^{5,6}$. Moreover, patients with multifocal IOL (MFIOL) implantation have higher expectations and dissatisfaction of postoperative quality of vision and occasional refractive surprises necessitating spectacle wear are often unacceptable to these patients ${ }^{7}$. Kamiya et al reported a series of 50 eyes of unhappy patients that underwent MFIOL explantation. Their survey showed that the most common reasons for MFIOL explantation were decreased contrast sensitivity, followed by photic phenomenon, unknown origin including neuroadaptation failure, incorrect IOL power, preoperative excessive expectation, IOL dislocation/decentration, and anisometropia ${ }^{7}$.

IOL opacification has been observed as an isolated phenomenon for polymethylmethacrylate (PMMA) and silicone materials or serially for acrylic materials mostly hydrophilic. Gartaganis et al ${ }^{8}$ demonstrated the calcification pattern of the hydrophilic IOL with a hydrophobic surface (Lentis LS-502-1) and they concluded that despite the hydrophobic surface, calcification can be developed from the hydrophilic subsurface of the IOL. This is in line with our laboratory investigation, which confirmed calcium depositions in explanted Lentis surface. They also noted that patients that underwent a combine phacoemulsification and pars plana vitrectomy (PPV) with silicone oil injection had the shortest intervals of IOL opacification, despite the intact posterior capsule and subsequently no direct contact between the IOL and the silicon oil. In our case series we did not have any combined procedures or any postphacoemulsification PPV.

Opacification of hydrophilic IOL of various lens designs have been reported over the past twenty years ${ }^{9-}$ ${ }^{14}$. This can be categorised into primary and secondary or false calcification. Primary IOL calcification can occur due to a variety of reasons, including improper formulation of the polymer, faulty packaging, forceps-related impressions, IOL fabrications and the presence of certain viscoelastic substances ${ }^{14}$. This calcification appears to be either in the surface of the IOL or in the substance of the lens. Secondary calcification is thought to be induced by intracameral gas (sulphur hexafluoride or perfluoropropane) or air, during Endothelial Keratoplasty (EK) surgery ${ }^{15}$ or simply a remnant of gas. The proposed mechanism is that the gas bubble induces local damage to the exposed IOL optic surface, which may protrude through the pupillary aperture ${ }^{16}$.

All our cases are considered as primary IOL opacification. This is similar to the outcome of other studies, where the vast majority developed primary IOL opacification ${ }^{17,18}$. The time of opacified Lentis explantation in our department varied from 4 to 8 years postoperatively ( $64.5 \pm 16.7$ months). This interval time is relatively close to Gurabardhi et al report of $49 \pm 14.4$ months, but much longer than Bompastor-Ramos et al $29.15 \pm 9.57$. This may suggest a delay in the initial diagnosis as few patients referred from other hospitals or a possible misdiagnosis particularly in patients that have been referred following 'unsuccessful' YAG laser capsulotomy. 
In our study, visual acuity improved in all eyes following IOL exchange, despite the challenges. Importantly, none of our patients were left aphakic and they all had IOL explantation and secondary lens implantation in one procedure. Interestingly, 3 out of 5 eyes that had within the bag secondary lens were implanted with a multifocal IOL, while in two eyes with previous YAG laser capsulotomy one IOL was placed in the sulcus and the other one in the anterior chamber. This highlights the importance of preserving the capsular bag before and during IOL exchange to maximise the chance of in the bag implantation. In previous series comorbidities such as diabetes, glaucoma, and uveitis were considered as risk factors ${ }^{19-21}$. In our sample there were no significant comorbidities and we did not record any early or late postoperative complications, but this is likely to be limited by the small number of subjects and relatively young patients' age.

In conclusion, IOL exchange for multifocal IOL opacification improved visual acuity in all our subjects. Surgical planning must take into account capsular bag status and the impossibility of in-the-bag IOL implantation. Moreover, when consenting patients for such procedures, patients must be warned of additional risks of zonular dialysis, vitreous loss, retinal detachment and need for potential ACIOL with its associated sequel of complications. It is also important to remember that YAG laser posterior capsulotomy should be considered carefully if there is a suspicion of IOL opacification, as it makes certain the need for anterior vitrectomy thus increasing the risk of retinal detachment after surgery and restricts the surgical options of secondary IOL implantation including in-the-bag IOL exchange with MFIOL.

\section{Declarations}

\section{Author contributions}

All authors contributed to the study conception and design. Material preparation, data collection and analysis were performed by Maria Phylactou, Nizar Dina and Francesco Matarazzo. All authors equally wrote the manuscript. All authors read and approved the final manuscript.

\section{Compliance with Ethical Standards}

Conflict of Interest: Author MP, ND, FM and VM declare that they have no conflict of interest.

Ethical approval: This article does not contain any studies with human participants or animals performed by any of the authors.

Informed consent: Informed consent was obtained from all individual participants included in the study.

Funding: All authors have no financial disclosure.

\section{References}


1. Packer M, Chu YR, Waltz KL et al (2010) Evaluation of the aspheric tecnis multifocal intraocular lens: one-year results from the first cohort of the Food and Drug Administration clinical trial. Am J Ophthalmol 149(4):577-584

2. Cillino S, Casuccio A, Di Pace F et al (2008) One-year outcomes with new-generation multifocal intraocular lenses. Ophthalmology 115(9):1508-1516

3. Gierek-Ciaciura S, Cwalina L, Bednarski L, MrukwaKominek E (2010) A comparative clinical study of the visual results between three types of multifocal lenses. Graefes Arch Clin Exp Ophthalmol 248(1):133-140

4. Alfonso JF, Fernandez-Vega L, Senaris A, Montes-Mico R (2007) Quality of vision with the Acri. Twin asymmetric diffractive bifocal intraocular lens system. J Cataract Refract Surg 33(2):197-202

5. Mamalis N, Brubaker J, Davis D, Espandar L, Werner L (2008) Complications of foldable intraocular lenses requiring explantation or secondary intervention 2007 survey update. J Cataract Refract Surg 34:1584-1591

6. Marques N, Marques DMV, Osher RH, Freitas LL (2008) Longitudinal study of intraocular lens exchange. Ophthalmology 115:73-79

7. Kamiya K, Hayashi K, Shimizu K, Negishi K, Sato M, Bissen-Miyajima H (2014) Multifocal Intraocular Lens Explantation: A Case Series of 50 Eyes. Am J Ophthalmol 158:215-220

8. Gartaganis S, Prahs P, Lazari E, Gartaganis P, Helbig H, Koutsoukos P (2016) Calcification of Hydrophilic Acrylic Intraocular Lenses with a Hydrophobic Surface: Laboratory Analysis of 6 Cases. Am J Ophthalmol 168:68-77

9. Park JC, Habib NE, Moate RM (2015) Intraocular lens opacification after corneal endothelial keratoplasty: electron microscopy and x-ray element spectroscopy analysis. J Cataract Refract Surg 41:140-145

10. Schmidinger G, Pemp B, Werner L (2013) Opacification of an intraocular lens: calcification of hydrophilic intraocular lenses after gas tamponade of the anterior chamber]. Ophthalmologe 110:1066-1068

11. Werner L, Wilbanks G, Nieuwendaal CP et al (2015) Localized opacification of hydrophilic acrylic intraocular lenses after procedures using intracameral injection of air or gas. J Cataract Refract Surg 41:199-207

12. Dhital A, Spalton DJ, Goyal S et al. Calcification in hydrophilic intraocular lenses associated with injection of intraocular gas. Am J Ophthalmol 2012;153: 1154-1160 e1

13. Bang SP, Moon K, Lee JH, Jun JH, Joo CK (2019) Subsurface calcification of hydrophilic refractive multifocal intraocular lenses with a hydrophobic surface: a case series. Medicine 98:50(e18379)

14. Yamashita K, Hayashi K, Hata S (2020) Toric Lentis Mplus intraocular lens opacification: A case report. American Journal of Ophthalmology Case Reports 18:100672

15. Bhalla M, El-Haddad O, Maurino V Opacified hydrophilic intraocular lens following DMEK. Eye (2020) 
16. Marcovich AL, Tandogan T, Bareket M et al (2018) Opacification of hydrophilic intraocular lenses associated with vitrectomy and injection of intraocular gas. BMJ Open Ophthalmol 3:e000157

17. Gurabardhi M, Heike H, HEnning A, Werner L, Pham DT (2018) Serial intraocular lens opacification of different designs from the same manufacturer: Clinical and light microscopic results of 71 explant cases. J Cataract Refract Surg 44:1326-1332

18. Bompastor-Ramos P, Povoa J, Lobo C, Rodriguez AE, Alio JL, Werner L, Murta JN (2016) Late postoperative opacification of hydrophilic-hydrophobic acrylic intraocular lens. J Cataract Refract Surg 42:1324-1331

19. Lim AKE, Goh PP, Azura R, Miriam I (2011) Opacification of AcriFlex 50CSE hydrophilic acrylic intraocular lenses. J Cataract Refract Surg 37:655-659

20. Pandey SK, Werner L, Appie DJ, Kaskalohlu M (2002) Hydrophilic acrylic intraocular lens optic and haptics opacification in a diabetic patient: bilateral case report and clinicopathologic correlation. Ophthalmology 109:2042-2051

21. Lee D-H, Seo Y, Joo C-K (2002) Progressive opacification of hydrophilic acrylic introcular lenses in diabetic patients. J Cataract Refract Surg 28:1271-1275

\section{Other Cited Material}

23. Field Safety Notice from Oculentis GmbH: Recall for LENTIS HydroSmart foldable intraocular lenses in glass vials. Dec 8, 2014, Bundesinstitut für Arzneimittel und Medizinprodukte (BfArM). Available at: Urgent Field Safety Notification Oculentis GmbH 2014-001 2014-12-04 Voluntary recall LENTIS HydroSmart foldable Intraocular lens

24. Field Safety Notice from Oculentis GmbH: Recall for Lentis L or LS or LU by Oculentis BV. Sep 21, 2017, Bundesinstitut für Arzneimittel und Medizinprodukte (BfArM). Available at: Field Safety Notice Urgent - Field Safety Notice Recall Lentis foldable Intraocular lenses

25. Oculentis Intraocular Lens Investigation. Foundation for Research and Technology Hellas, Institute of Chemical Engineering Sciences (Forth/ICE-HT), University of Patras, Greece. 30/08/2017. Available at:

\section{Figures}




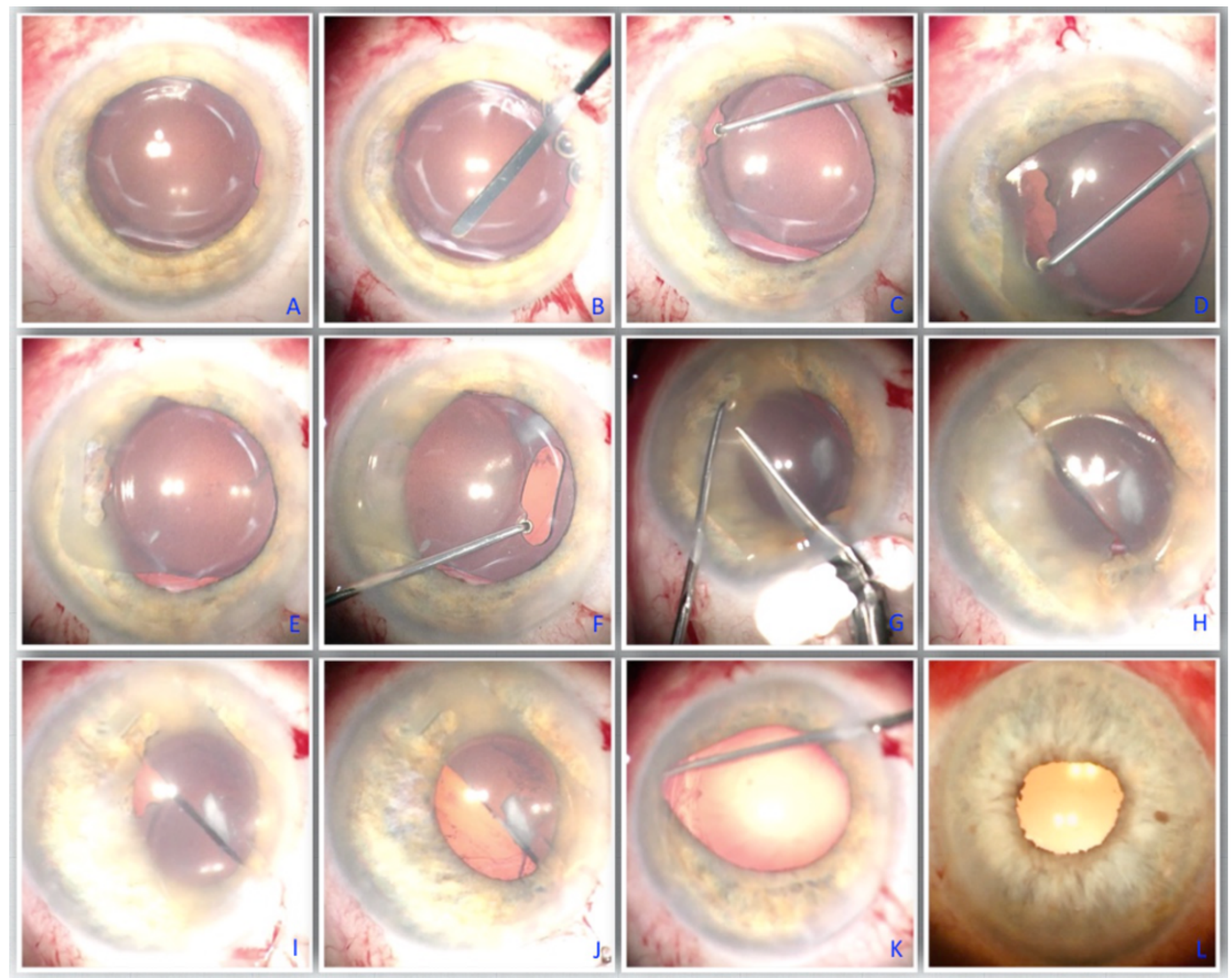

Figure 1

Surgical steps of IOL exchange (A-L).

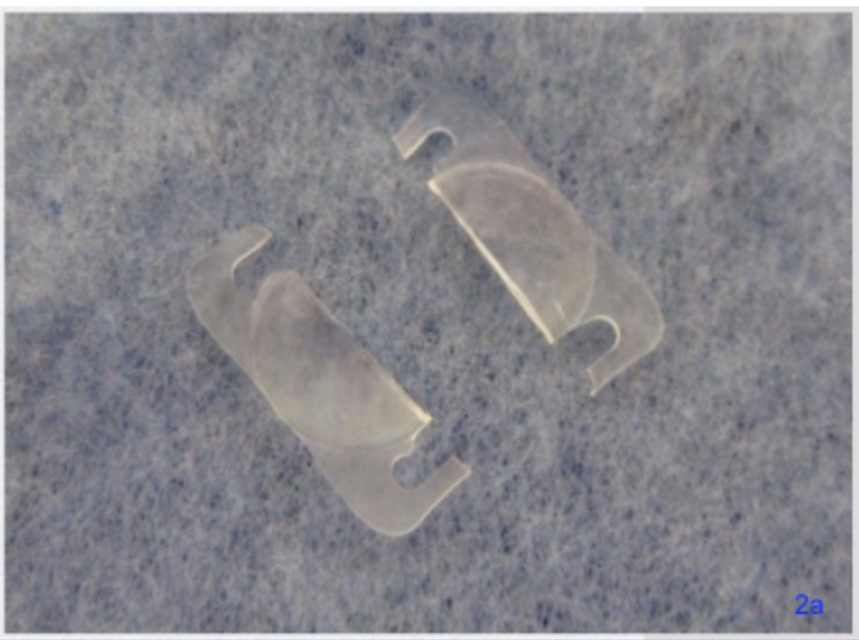


Figure 2

Explanted multifocal Lentis LS-313. (2a) Gross image showed a diffused whitish discoloration of the explanted IOL. (2b) Light microscopy examination with von Kossa stain demonstrated the outline of the optic and haptics with stippled material, which is consistent with calcification. 